\title{
Mullerian Duct Cyst in Vagina Mimicking as Rectocele
}

\author{
Bhatara $\mathbf{U}^{1}$, Padmasri R', Begum $\mathbf{R}^{2}$ \\ ${ }^{1}$ Department of Obstetrics and Gynaecology, Sapthagiri Institute of Medical sciences and Research, Bangalore, \\ India, ${ }^{2}$ Department of Obstetrics and Gynaecology, Eskay Hospital, Bangalore, India.
}

Received: March 18, 2015 ; Accepted: August 25, 2015

Mullerian duct cysts of vagina are rare. Precise diagnosis of Mullerian cyst of vagina requires clinical, radiological and histopathological examination. Here case of Mullerian cyst is presented which was mimicking rectocele and main complaint during presentation was difficulty in intercourse.

Keywords: mullerian duct cyst; rectocele; vaginal wall cyst.

\section{DEAR EDITOR,}

Mullerian duct cyst of vagina is rare. Mullerian duct cysts are mainly present in third and fourth decade of life. ${ }^{1}$ Incidence is about $30 \%-40 \%$ of all vaginal cysts. $^{2}$ It is lined by columnar endocervical-like or cuboidal epithelium present anywhere along the path of development of Mullerian duct therefore it can be anterior, lateral or post vaginal wall. Diagnosis is made after thorough clinical examination, Magnetic Resonance Imaging (MRI) scan and histopathological examination. Mostly these cysts are small and asymptomatic do not cause any problem. ${ }^{3}$ If any discomfort arises; treatment consists of excision of cyst so that recurrence is prevented. ${ }^{4}$

The patient had complaint of swelling in vagina since one month. She had complained of cyst two years ago for which she was operated. At that time drainage of the cyst was done and wall was cauterized. The cyst had recurred. After removal of cyst for first time she had undergone full term vaginal delivery. On examination there was swelling in posterior vaginal wall of $4 \times 5 \mathrm{~cm}$ size. It was soft and there was no cough impulse present. There was no associated descent of uterus or presence of cystocele/ rectocele. Our differential diagnosis was that of traumatic inclusion cyst post-delivery or rectocele. Ultrasonography was suggestive of cyst with no attachment with surrounding structures and provisional diagnosis of Mullerian duct cyst was made. For confirmation

\section{CORRESPONDENCE}

Dr Urvashi Bhatara

Department of Obstetrics and Gynaecology, Sapthagiri Institute of Medical sciences and Research, Bangalore, India Email: urvashibhatara@gmail.com

Phone: +91-9448696741
MRI scan was done and diagnosis of Mullerian duct cyst was confirmed. She underwent cyst removal. Posterior vaginal mucosa was infiltrated with saline and then whole of the cyst was removed. It contained mucinous material and cyst wall sent for histopathological examination, which was suggestive of cuboidal cells. Position of cyst, MRI scan and histopathological examination helped in confirmation of the diagnosis of Mullerian duct cyst.

Cysts can occur in any part of body. In vagina also many types of cysts are seen. Vaginal cysts are rare and they are mostly asymptomatic and are detected as incidental finding during gynecological examination. Incidence is 1 in $200 .{ }^{5}$ These include inclusion cysts following trauma or surgery, Bartholin gland cysts, cysts of Skene glands, Gartner cysts arising from remnants of mesonephric ducts and Mullerian duct cysts arising from remnants of paramesonephric ducts (Mullerian cyst). Mullerian duct cysts are rare and are present in males and females. It mainly presents as midline masses and may be present anywhere along the path of development of Mullerian duct. Therefore it can be present in anterior, lateral or posterior vaginal wall. In vagina it is present mainly in anterior vaginal wall, ${ }^{6}$ posterior vaginal wall Mullerian duct cyst is still rarer. ${ }^{7}$

Mullerian ducts are responsible for development of tubes, uterus and upper part of vagina. Anomalies thus range from problems in tubes to those in uterus and also in vagina. These problems may be trivial or they may be severe affecting fertility or may create problems in adolescence. Anomalies are noted only when there is any problem to the patient, which requires clinical intervention. 
It has to be differentiated from Bartholin's cyst, inclusion cyst and Gartner's cyst. Differentiation of Mullerian duct cyst from Gartner cyst is very important as Gartner cyst is mainly associated with ureteral and renal abnormalities, including congenital ipsilateral renal dysgenesis or agenesis, crossed fused renal ectopia, and ectopic ureters while Mullerian duct cyst may be associated with structural uterine anomalies (ipsilateral Mullerian duct obstruction, bicornuate uteri, and uterus didelphys) and diverticulosis of the fallopian tubes. ${ }^{8}$

Differentiating point is clinical examination, radiological findings and histopathology examination. Clinically Mullerian duct cyst and Gartner cysts are mainly seen in midline whereas Bartholin's is detected in postero-lateral aspect and is commonly infected and epidermal cyst are mainly detected in area where there is history of surgical incisions. ${ }^{9}$

MRI helps in diagnosis. It is detected as hyper intense area in MRI scan. ${ }^{10} \mathrm{MRI}$ also helps to detect any other associated anomalies and whether cyst is connected with surrounding structures or not. This is important as anomalies may be associated in Mullerian duct cyst and Gartner cyst.

Finally confirmation is done by histopathological examination. Mullerian duct cyst is lined by columnar endocervical-like or cuboidal epithelium. Gartner's duct cysts are lined by cuboidal epithelium.

Epidermal inclusion cysts are lined by stratified nonkeratinizing squamous epithelium. Bartholin's duct cysts are lined by transitional, mucin-rich columnar or squamous epithelium and were frequently accompanied by inflammation. ${ }^{11}$ Normally Mullerian cyst duct are asymptomatic and thus rarely require treatment but sometimes cyst will grow to big size and will obstruct normal labor, cause coital problems, voiding problem and pain due to infection. ${ }^{12}$ If any of these problems exists then excision has to be carried out. If during that time we are not aware of different presentations of disease we will land up in giving wrong treatment. As in this case drainage and cauterization was done which was not effective, as it required full removal of cyst wall.

\section{CONCLUSIONS}

In present scenario due to easy availability of imaging modalities; more and more diagnosis are made and treatment is given. It is now important that clinicians should be well versed with not only common problems but also rare entities. It is also important that clinicians should have knowledge of imaging techniques required in their field and training modalities should be made so that they can be trained in imaging techniques. In today's changing scenario it is important that clinician should be aware of not only clinical skills but also knowledge of anatomy, embryology, pathology, microbiology, pharmacology, radiology and other medical aspects required in their field.

\section{DISCLOSURE}

The authors report no conflicts of interest in this work. No violation of human rights and safety.

Funding: Nil

\section{REFERENCES}

1. Devaraju S, Nerli RB, Hiremath MB. A Large Mullerian Duct Cyst Presenting as an Abdominal Mass With Ipsilateral Renal Agenesis: An Unusual Presentation. Nephrourol Mon. 2012;4(4):640-3.

2. Eric S, William I. Urethral Diverticula and Other Periurethral Masses. Vaginal Surgery for Incontinence and Prolapse. Springer. 2006; 271.

3. Pafiti K, Grapsa D, Papakonstantinou K, Kairi-Vassilatou E, Xasiakos D. Vaginal cysts: a common pathologic entity revisited. Clin Exp Obstet Gynecol. 2008;35(1):41-4..

4. Toy H, Yazici F. Female Genital Tract Cysts. Eur J Gen Med. 2012;9(1):21-6.

5. Sreelatha S, Ashok K, Anitha G, Tejaswini B. An unusual case of posterior vaginal wall cyst. Int J Reprod Contracept Obstet Gynecol.2014; 3(1):282-4.

6. Fox H, Buckley CH. Atlas of Gynaecological Pathology. Springer. Current Histopathology. Volume 5;1983.
7. Jayaprakash S, Lakshmidevi M, Sampath Kumar G. A rare case of posterior vaginal wall cyst. BMJ Case Report 2011; 2011.

8. Sherer D, Abulafia O. Transvaginal Ultrasonographic: Depiction of a Gartner Duct Cyst. J Ultrasound Med. 2001;20:1253-5.

9. Marisa N, Esther O. Chapter 3. Benign diseases of vagina. Gyencologic Pathology. Elsevier: 2009.p.97.

10. Esra M, Ceyla B, Fuldem Y, Zeynep G, Bahar G, Mehmet C. Mullerian Duct Cyst with ipsilateral renal agenesis: RI findings. Marmara Med J. 2009;22(1): 064-7.

11. Pafiti K, Grapsa D, Papakonstantinou K, Kairi-Vassilatou E, Xasiakos D. Vaginal cysts: a common pathologic entity revisited. Clin Exp Obstet Gynecol. 2008;35(1):41-4.

12. Valecha S, Shah N, Gandhewar M, Shende P. Rare case of prolapsing vaginal cyst. J South Asian Feder Obstet Gynecol. Jan-April 2013;5(1):40-1. 